$26^{\text {th }}$ ICAF Symposium - Montréal, 1-3 June 2011

ICAF 2011 Structural Integrity : Influence of Efficiency and Green Imperatives :

Proceedings of the 26th Symposium of the International Committee on Aeronautical Fatigue.

Canada, pp753-770. Ed. Jerzy Lomorowski

\title{
Life Extension Techniques for Aircraft Structures - Extending Durability and Promoting Damage Tolerance through Bonded Crack Retarders
}

\author{
P E Irving ${ }^{1}$, X Zhang ${ }^{1}$, J Doucet ${ }^{1}$, D Figueroa-Gordon ${ }^{1}$, \\ M Boscolo \\ M Heinimann $^{2}$, G Shepherd ${ }^{3}$, M E Fitzpatrick ${ }^{4}$, D Liljedahl ${ }^{4}$ \\ ${ }^{1}$ Cranfield University, Cranfield, Bedford, UK \\ ${ }^{2}$ Alcoa Technical Center, Alcoa Center, PA, USA \\ ${ }^{3}$ Airbus Operations Limited, Filton, Bristol BS34 7AR, UK \\ ${ }^{4}$ Materials Engineering, The Open University, Milton Keynes, \\ UK
}

\begin{abstract}
This paper explores the viability of the bonded crack retarder concept as a device for life extension of damage tolerant aircraft structures. Fatigue crack growth behaviour in metallic substrates with bonded straps has been determined. SENT and $\mathrm{M}(\mathrm{T})$ test coupons and large scale skin-stringer panels were tested at constant and variable amplitude loads. The strap materials were glass fibre polymer composites, GLARE, AA7085 and Ti-6Al$4 \mathrm{~V}$. Comprehensive measurements were made of residual stress fields in coupons and panels.

A finite element model to predict retardation effects was developed. Compared to the test result, predicted crack growth life had an error range of $-29 \%$ to $61 \%$.

Mechanisms and failure modes in the bonded strap reinforced structures have been identified. The strap locally reduces substrate stresses and bridges the crack faces, inhibiting crack opening and reducing crack growth rates. In the absence of residual stress, global stiffness ratio accounts for effects of both strap modulus and strap cross section area. In elevated temperature cure adhesives, retardation performance was best in aluminium and GLARE strap materials, which have the closest thermal expansion coefficient to the substrate. Strap materials of high stiffness and dissimilar thermal expansion coefficient such as titanium had poor retardation characteristics.
\end{abstract}




\section{INTRODUCTION}

Requirements for green aircraft can be interpreted as lighter aircraft, and/or aircraft with extended life and less maintenance. Extended lives can be achieved on safe life designs by increasing material fatigue strength and reducing stress concentration factors. Requirements for damage tolerance in extended-life aircraft imply real increases in fatigue crack growth resistance, fracture toughness and residual strength. Extensive research over the past 30 years suggests that little improvement in crack growth resistance in monolithic aluminium alloys can be achieved through metallurgical innovation alone [1]. Indeed, if weight reduction is attempted via use of increased strength materials at augmented stress levels, fatigue crack growth rates increase rather than decrease, driven by the increased stress ranges. In turn damage tolerance of the structure will be reduced.

Alternative approaches to increased damage tolerant life include use of fibre-metal laminates, such as GLARE, or the use of bonded features such as bonded stringers, bonded repairs, and the recently developed bonded crack retarder concepts [2-5]. These techniques have the capability to produce step changes in resistance to fatigue crack growth in metallic structural components. The potential to improve crack growth resistance has been demonstrated in a number of previous papers [25].

However, many details of application of bonded retarders and accurate modelling of their effects remain to be established. Previous work shows that cracks propagating in substrates containing bonded straps have growth rates which are not exclusively determined by the stress intensity calculated from substrate geometry and stress. Calculation of growth rates requires data characterising the strapsubstrate stiffness ratio and adhesive strength and toughness as well as the position of the crack tip in relation to the strap location.

In this research coupon samples of 7085 aluminium alloy containing bonded straps of a wide range of geometry and modulus have been manufactured and tested to characterise fatigue crack growth resistance. The local stress state around the strap and crack has been modelled using finite element analysis, and the residual stress field induced by thermal expansion mismatch between the strap and substrate has been measured using neutron diffraction. Fracture mechanics analysis was performed using finite elements to calculate the effect of the strap on stress intensity factors at a range of crack tip locations. Output from the numerical models was used to interpret the experimental test results and to extend them to predict optimum strap properties and geometry for life extension at minimum weight and cost.

The performance of bonded straps was further evaluated by testing 5-stringer integrally stiffened panels with and without bonded straps under a realistic flight load spectrum. Panels with bonded straps demonstrated significant crack growth 
retardation resulting in increased panel lives by a factor of 2 at stress levels increased by $20 \%$ (to account for the additional cross sectional area of the straps).

These results permit selection of strap materials and geometry to optimise fatigue crack growth resistance in aluminium alloys. The implications for life extension and damage tolerance capability in aircraft will be discussed in the paper.

\section{COUPON SPECIMENS}

The substrate metal for all the testing work was aluminium alloy 7085-T7651

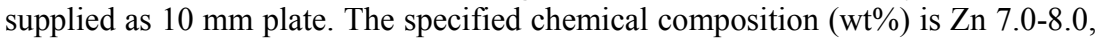
$\mathrm{Mg} 1.2-1.8, \mathrm{Cu} 1.3-2.0, \mathrm{Fe}<0.08, \mathrm{Si}<0.06, \mathrm{Zr} 0.08-0.15$. Measured mechanical properties from [6] are listed in Table 1.

Table 1 Measured tensile mechanical properties of supplied 7085 plate [6]

\begin{tabular}{cccc}
\hline Sample orientation & $0.2 \%$ proof / MPa & UTS / MPa & Elongation $/ \%$ \\
\hline Longitudinal & 476 & 510 & 7.3 \\
Transverse & 462 & 503 & 5.0 \\
\hline
\end{tabular}

Coupon tests were performed primarily using single edge notched tension (SENT) samples $140 \mathrm{~mm}$ wide, $400 \mathrm{~mm}$ long. Straps were bonded to one side of the specimens at the location shown in Fig. 1(a). The initial notch was $17 \mathrm{~mm}$ long. Sample length between the grip ends was $270 \mathrm{~mm}$. Four strap materials were tested; these were fibre-metal laminate GLARE-1(3/2), titanium alloy Ti-6Al-4V, glass fibre reinforced polymer (GFRP) Hexcel 913G-E-5-30\%, and the substrate material AA 7085. Strap nominal dimensions were $200 \times 20 \times 2 \mathrm{~mm}(1.8 \mathrm{~mm}$ for the GLARE strap). For selected strap materials a range of other geometries were tested. The strap edge was located $20 \mathrm{~mm}$ from the notch tip. Mechanical properties of the strap materials are given in Table 2. For the SENT geometry all tests were performed under constant amplitude loading.

Tests were also conducted using the middle cracked tension $\mathrm{M}(\mathrm{T})$ geometry. These tests were used to establish the effects of higher substrate stresses and also variable amplitude loading. The $\mathrm{M}(\mathrm{T})$ samples were the same overall dimensions as the SENT but with a centre notch and with the strap edge located $13.5 \mathrm{~mm}$ from the centre line of the specimen as shown in Fig. 1(b).

In addition to tests on specimens with a bonded strap, samples of 7085 were tested to determine the substrate fatigue crack growth characteristics at $R$ ratios of 0.1 , 0.3 and 0.6 .

Aluminium substrates were surface treated following ASTM D 2651-90 prior to applying the primer BR 127 to the side to be reinforced. Retarder straps were cut to size and bonded to the samples using either FM94, a high temperature curing film 
adhesive or Redux 810, a room temperature curing adhesive. FM 94 was cured in an autoclave following Cytec recommended procedures at $120^{\circ} \mathrm{C}$. The residual stress field induced by thermal expansion mismatch between the strap and substrate was measured using the neutron diffraction technique [7]. The REDUX 810 was cured at room temperature for 5 days.

Table 2 Adhesive and strap material properties

\begin{tabular}{c|c|c|c|c}
\hline Material & FM 94 & GLARE-1 (3/2) & GFRP & Ti-6Al-4V \\
\hline$E_{11}(\mathrm{GPa})$ & 1.9 & 65 & 40 & 114 \\
$E_{22}(\mathrm{GPa})$ & 1.9 & 48 & 10 & 114 \\
$G_{12}(\mathrm{GPa})$ & 0.62 & 16 & 5 & 44 \\
$v_{12}$ & 0.52 & & 0.28 & 0.34 \\
$\alpha_{11}\left(\mu \varepsilon^{\circ} \mathrm{C}^{-1}\right)$ & $/$ & 16.3 & 3.6 & 8.6 \\
$\alpha_{22}\left(\mu \varepsilon^{\circ} \mathrm{C}^{-1}\right)$ & $/$ & 25.5 & 21 & 8.6 \\
$\rho\left(\mathrm{g} \mathrm{cm}^{-3}\right)$ & 1.1 & 2.49 & 2 & 4.5 \\
\hline
\end{tabular}

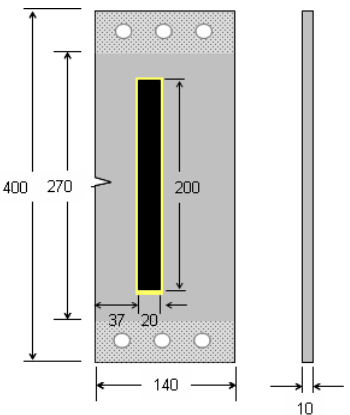

(a) SENT specimen

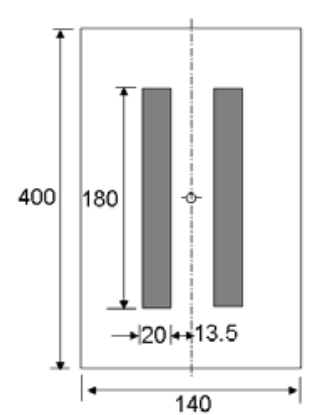

(b) $\mathrm{M}(\mathrm{T})$ specimen

Fig 1 Coupon test samples and dimensions (unit: $\mathrm{mm}$ ).

\section{COUPON TEST RESULTS}

Effects of strap/substrate stiffness ratio on fatigue crack growth rates

Results reported here refer to the SENT samples bonded with the complete range of strap materials (GLARE, GFRP, Ti-6-4 and AA7085). These straps had a wide range of stiffness values, from $35 \mathrm{GPa}$ for GFRP to $114 \mathrm{GPa}$ for the titanium alloy (Table 2). In terms of material type there were metal (aluminium and titanium), polymer composite (GFRP) and fibre-metal laminate. The other parameter in the expression for the global stiffness ratio $(\mu)$, eq. 1 , is the cross section area of the 
strap, which depends on the thickness and width of the strap. In a large number of the tests the strap width was kept constant and the thickness changed to vary the strap cross section area.

$$
\mu=\frac{\sum\left(E_{\text {strap }} A_{\text {strap }}\right)}{E_{\text {substrate }} A_{\text {substrate }}+\sum\left(E_{\text {strap }} A_{\text {strap }}\right)}
$$

Figure 2 shows the effect on growth rate of changing global stiffness ratio $\mu$ from 0.02 to 0.16 , a factor of 8 change, in comparison with fatigue crack growth rates in the unstrapped sample at the same nominal $\Delta \sigma$ value of $18.6 \mathrm{MPa}$. In these tests the straps were bonded using Redux 810 at room temperature; hence there was no residual stress present.

In comparison with the unstrapped substrate, all of the samples with straps show a reduction in growth rate. The reduction is least for the GFRP strap $(\mu=0.02)$ and greatest for the titanium $(\mu=0.16)$. It can also be noted that the retardation effects begin when the crack tip is at least $5 \mathrm{~mm}$ from the strap edge, immediately at the start of the test. Hence constraint of crack opening by the strap plays no role in retardation at this point, but can only be a consequence of local substrate stress reduction by the presence of the strap. The extent of retardation gradually reduces as the crack propagates under the strap. Retardation is still present when the crack tip is beyond the strap, but the difference in growth rates between the various strap materials is slowly reducing, becoming zero when the crack tip is $20 \mathrm{~mm}$ beyond the strap edge.

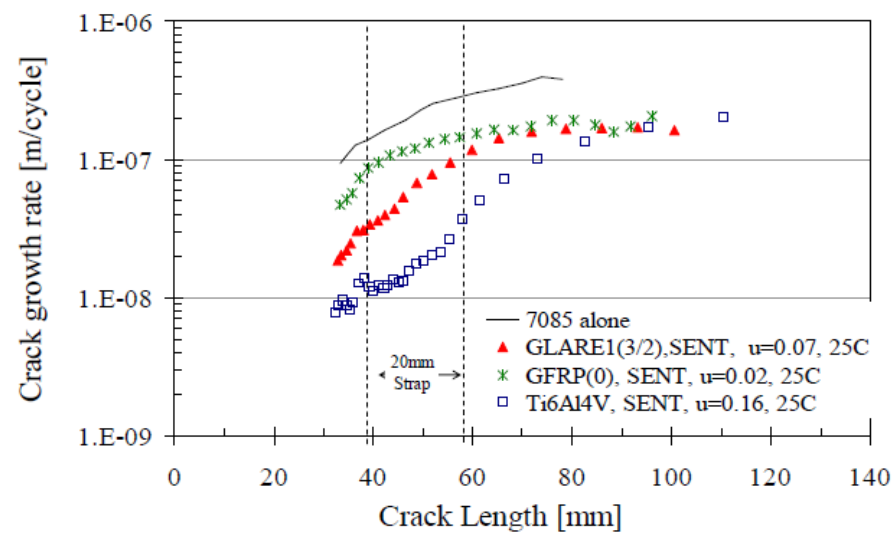

Fig. 2 Effect of global stiffness ratio $(\mu)$ on fatigue crack growth rates as the crack approaches and tunnels under the strap; $\left(20^{\circ} \mathrm{C}, \Delta \sigma=18.6 \mathrm{MPa}\right)$. 
$\underline{\text { Residual stresses in substrate due to elevated temperature curing process }}$

Results reported here refer to the SENT samples bonded with the complete range of strap materials. Longitudinal residual stress profiles for the strap reinforced SENT specimens are shown in Fig. 3, [8]. The measuring position was $2.5 \mathrm{~mm}$ from the strap/substrate bond interface. For the GFRP and GLARE straps the residual stresses are much lower than that of the Ti-6Al-4V alloy. To summarise, measured maximum longitudinal stresses in the substrate are listed in Table 3.

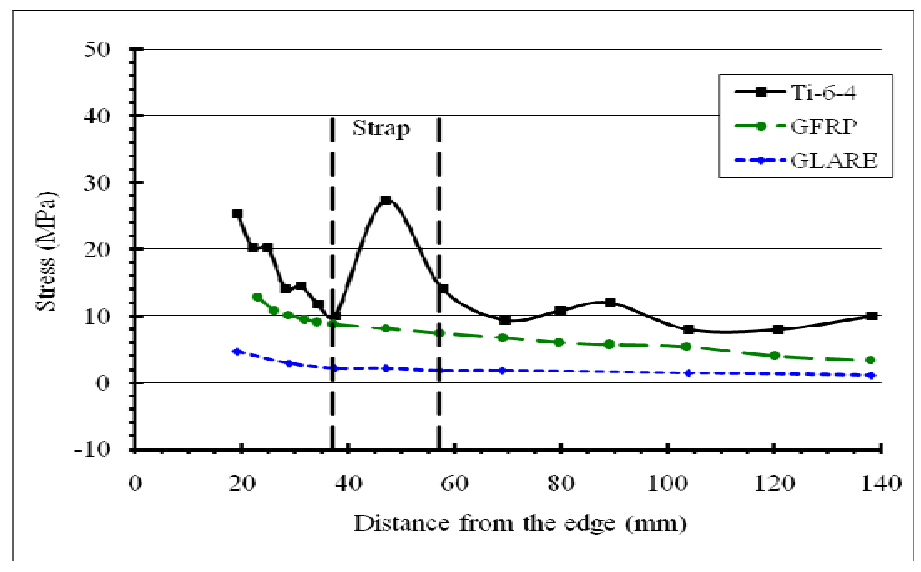

Fig. 3 Measured longitudinal residual stresses (average values) in a $10 \mathrm{~mm}$ thick SENT sample bonded with $20 \mathrm{~mm}$ wide, $200 \mathrm{~mm}$ long straps . Measured residual stresses are $2.5 \mathrm{~mm}$ from the bond interface.

Table 3 Measured longitudinal residual stresses for the different strap materials

\begin{tabular}{l|l|l}
\hline Strap material & $\begin{array}{l}\text { Strap dimensions } \\
\text { length } \mathrm{x} \text { width } \mathrm{x} \text { thickness } \\
(\mathrm{mm})\end{array}$ & $\begin{array}{l}\text { Maximum residual stress } \\
\text { in substrate }(\mathrm{MPa})\end{array}$ \\
\hline Ti-6A1-4V & $200 \times 20 \times 2$ & $28 \sim 30$ \\
GFRP & $200 \times 20 \times 2$ & $10 \sim 12$ \\
GLARE-1 & $200 \times 20 \times 1.8$ & $5 \sim 8$ \\
\hline
\end{tabular}

Effects of different strap materials at elevated temperature cure (at same $\mu$ )

The elevated temperature curing process used for FM94 produces tensile residual stresses in the aluminium substrate as the Coefficient of Thermal Expansion (CTE) of aluminium is greater than that of any of the strap materials, and if there is zero residual stress at the cure temperature of $120^{\circ} \mathrm{C}$, when the bond is fully cured, residual stresses will develop under and around the strap as it cools down to room temperature. The magnitude of the residual stress will depend on the mismatch between CTE of substrate and strap, and also on the stiffness mismatch of the 
substrate and strap and the thickness mismatch. For a strap-substrate system in which the strap covers all of the substrate area the substrate stress arising from thermal mismatch is:

$$
\sigma_{r e s}=\frac{\Delta T\left(\alpha_{s}-\alpha_{r}\right) E_{s} E_{r} t_{r}}{E_{s} t_{s}+E_{r} t_{r}}
$$

where, $\Delta T$ is the temperature change, $\alpha_{s}$ and $\alpha_{r}$ are CTE, $E_{s}$ and $E_{r}$ are elastic modulus, $t_{s}$ and $t_{r}$ are thicknesses of substrate and reinforcing strap, respectively.

In the absence of residual stresses, growth rates in samples with different strap materials but the same global stiffness ratio will be identical. Under elevated temperature curing, residual stresses will exist and differences in growth rate will be related to different residual stresses induced by different strap materials. The smallest residual stresses will have the best retardation effect. An example of this behaviour is shown in Fig 4 where straps of aluminium 7085, GLARE, titanium and unidirectional GFRP are compared. The optimum retardation behaviour is exhibited by the 7085 strap with zero residual stress, next is GLARE with a residual stress field of 5-8 MPa, GFRP and Ti-6-4 straps have much higher growth rates and have greater residual stresses than the field developed by GLARE. Similar growth rates in GFRP and Ti-6-4 reinforced coupons may be due to the fact that the titanium and the GFRP straps did not have identical stiffness ratios.

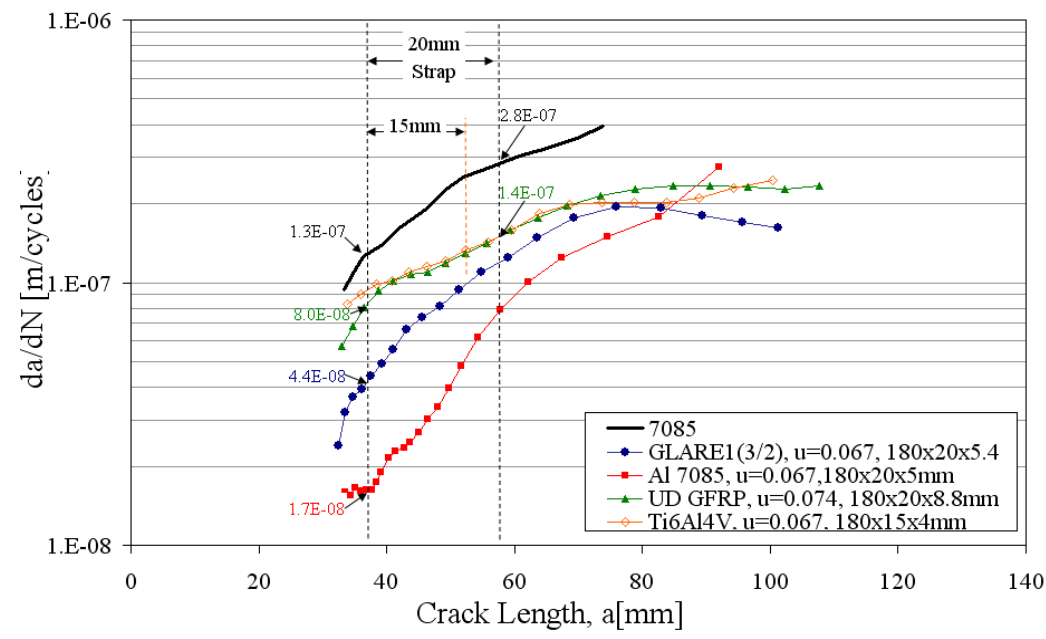

Fig. 4 Comparison of growth rates in samples with different strap materials having approximately the same value of $\mu=0.07$ and elevated temperature cure, showing influence of thermal residual stress. 
Substrate stress levels of $60 \mathrm{MPa}$

A number of tests were performed on $M(T)$ samples at substrate stresses of 60 MPa to establish the influence of stress level on the crack growth rate behaviour observed. An example of an equivalent comparison for aluminium, titanium and GLARE straps is shown in Fig 5, where growth rates are plotted against nominal (assuming no strap present) $\Delta \mathrm{K}$ instead of crack length, in order to make the comparison under high stress and different sample geometry \& crack length with substrate material. It can be seen that the behaviour is rather different to that seen in the SENT samples. Firstly the difference in crack growth rates is least at the start of the tests and steadily increased as the crack tips moved under the straps. This is the reverse of the behaviour observed in the SENT samples at low stresses. This difference may be related to differences in the residual stress field induced by the thermal cycles in the two geometries of sample. Secondly there is little difference in the growth rates in the three strap materials, although all of them show significant retardation compared with growth rates in the base material. Nominal $\Delta \mathrm{K}$ values are between 10 and $30 \mathrm{MPa} \sqrt{\mathrm{m}}$, instead of 8-12 $\mathrm{MPa} \sqrt{\mathrm{m}}$ for the stresses of 18.6 MPa used in the SENT samples.

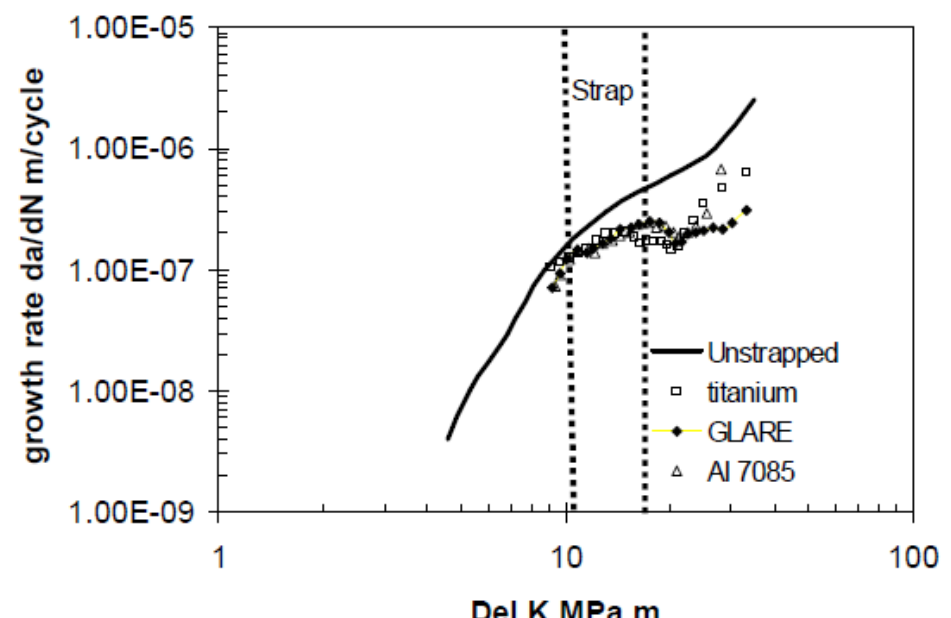

Fig. $5 \log d \mathrm{a} / \mathrm{dN}$ vs. nominal $\Delta \mathrm{K}$ for un-strapped and strapped (20 mm width) $\mathrm{M}(\mathrm{T})$ samples tested at substrate stress $\sigma_{\max }=60 \mathrm{MPa}, \mathrm{R}=0.1 ; \mu=0.07$ for titanium, GLARE and aluminium straps; adhesive FM 94 cured $120^{\circ} \mathrm{C}$.

The reduced effect of residual stress at larger values of $\Delta K$ is believed to arise from two sources. Firstly there is reduced effect of $R$ ratio changes on fatigue crack growth rates in the substrate as $\Delta \mathrm{K}$ values are increased [9]. Secondly, changes in the effective $\mathrm{R}$ ratio produced by a residual stress are expressed by the stress intensity factors resulting from the applied and residual stresses as in eq. (3). As the applied stresses $\sigma_{\min }$ and $\sigma_{\max }$ are increased, the corresponding stress intensity 
factors, $K_{\min }$ and $K_{\max }$, also increase and the effect of $K_{\text {res }}$ on $R_{\text {eff }}$ becomes proportionately less.

$$
R_{e f f}=\frac{K_{\min }+K_{r e s}}{K_{\max }+K_{r e s}}
$$

Variable amplitude load testing

A variable amplitude load spectrum representative of a transport aircraft upper wing cover was used to test the relative performance of different straps bonded to $\mathrm{M}(\mathrm{T})$ samples (all with $\mu=0.07$ ). The spectrum had a maximum substrate tensile stress of $49 \mathrm{MPa}$. The results are shown in Fig. 6, plotted as crack length vs. cycles where cycles are individual spectrum cycles. The data show that under the upper wing cover spectrum, the strap producing the longest life is GLARE, with a life more than double that of the unstrapped substrate. Next best is aluminium, followed by titanium and by GFRP. Under variable amplitude loading the differences in growth rates between the straps, possibly due to residual stress differences, are increased compared with those observed at $60 \mathrm{MPa}$ constant amplitude loading. This may be because of the reduced $\Delta \mathrm{K}$ values of the small cycles in the spectrum, which will occupy a range of the $\Delta \mathrm{K}$ vs. da/dN curve with greater mean stress sensitivity.

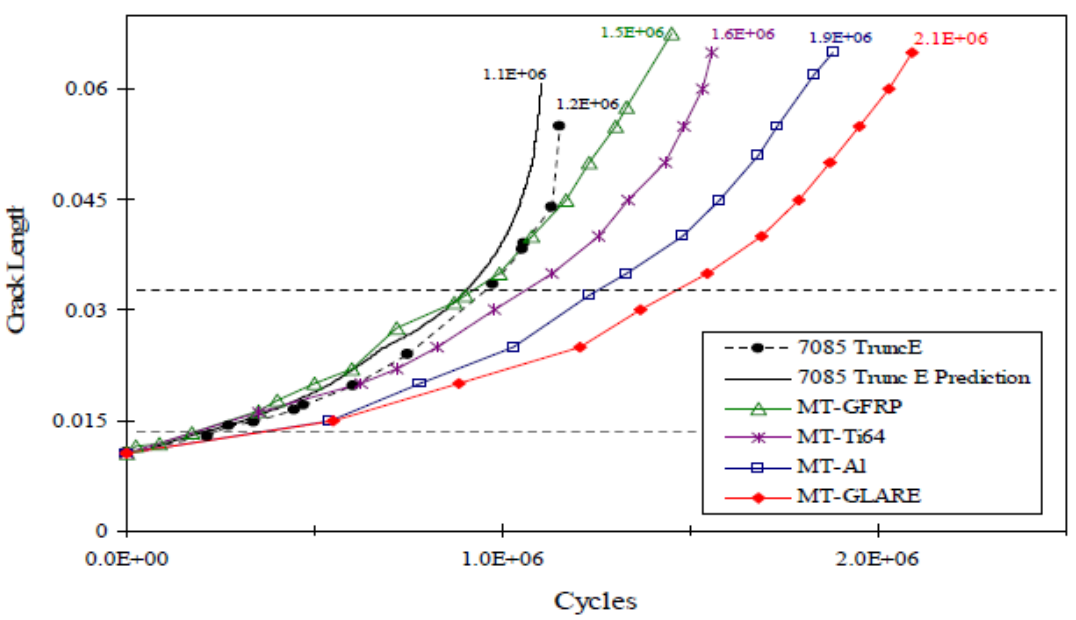

Fig. 6 Strap comparison: $\mu=0.07,120^{\circ} \mathrm{C}$ cure, spectrum loads $\sigma_{\max }=49 \mathrm{MPa}$.

Performance of strap materials - summary of effects of substrate stress \& spectrum A comparison of the performance of the different strap materials expressed as the ratio of strapped life to unstrapped life is shown in Fig. 7. This shows the life improvement factor for substrate stresses of $18.5 \mathrm{MPa}$ and $60 \mathrm{MPa}$ of constant amplitude (CA) loading compared with variable amplitude (VA) loading with 
maximum tensile stress of $49 \mathrm{MPa}$, all samples with $\mu=0.07$. Strap bonding was with FM 94 and a $120^{\circ} \mathrm{C}$ cure; hence residual stresses are present. The greatest difference between the straps was found at CA loading of $18.5 \mathrm{MPa}$, and least under the variable amplitude loading. GLARE straps were consistently the best, except for the small constant amplitude stress conditions. The life factor for GLARE is 1.8 for variable amplitude loading, 2.7 for the $60 \mathrm{MPa}$ loading and 2.4 for $18.5 \mathrm{MPa}$.

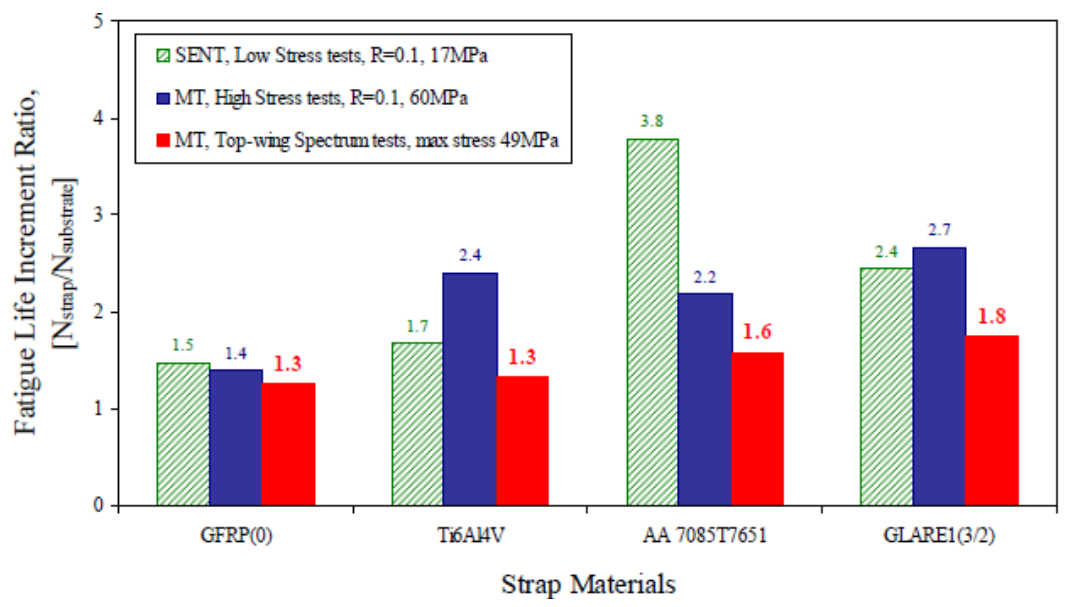

Fig. 7 Fatigue life increment ratio for different strap materials under constant amplitude $\left(\sigma_{\max }=18.5,60 \mathrm{MPa}, R=0.1\right)$ and variable amplitude $\left(\sigma_{\max }=49 \mathrm{MPa}\right)$ loads.

\section{COUPON MODELS}

\section{Crack growth modelling}

A two-dimensional finite element model has been developed, in which the substrate and straps are modelled by the plate elements and the adhesive is represented by a combination of the rigid and spring elements. This assembly of elements can mimic the interactions of strap, adhesive and substrate. The effective crack-tip stress intensity factor (SIF or $K$ ) of the substrate crack is calculated for each propagating crack length under the influences of the external loads, residual stresses, and strap and adhesive constraints. Adhesive disbond and/or delamination damage area is used to modify the substrate crack stress intensity factor, which is then used to predict the crack growth rates of the substrate plate using the material data developed from the coupon tests of the project. 
Predicted crack growth rates and lives for various plate and strap configurations are validated by coupon tests. A total of 13 different coupon samples have been modelled (SENT and $\mathrm{M}(\mathrm{T})$ with various strap materials and configurations). Comparing to the test result, predicted crack growth life has an error range of $-29 \%$ to $61 \%$. The absolute mean error is $20 \%$. Details of calculation and validation can be found in [10-11].

Stress transfer from cracked substrate to bonded straps

In order to estimate the stress distribution between the substrate and strap, a 3D model of a quarter of the $\mathrm{M}(\mathrm{T})$ sample was built using the commercial software ABAQUS ${ }$. As a demonstrator, aluminium alloy 2024-HDT is used for both the substrate and strap. The strap/substrate stiffness ratio is 0.215 calculated by eq. (1). A refinement of the mesh was developed at the crack path in order to get the best approximation of stress intensity at the crack tip. The analysis was linear elastic. A delaminated area was implemented in the model in order to take into account the phenomenon of delamination taking place in the samples. The applied stress was $70 \mathrm{MPa}$. Among several cases studied, the cases of a $26 \mathrm{~mm}$ half crack length in the substrate (crack is in middle of strapped region) and $48 \mathrm{~mm}$ half crack length (crack has passed the strapped region) are chosen to illustrate the results of the stress transfer from cracked substrate to bonded crack retarder, Fig. 8. As the straps were bonded on one side of the substrate only, secondary bending was observed in with a maximum deflection of $3 \mathrm{~mm}$ at the middle of the sample, Fig. 8(a).

Due to the secondary bending effect, the strap top surface is under compression and the bondline surface in tension. The mean stresses in the strap in the loading direction are illustrated in Fig. 8(b). In the no-crack case (1), the mean stress is about $15 \mathrm{MPa}$ at the middle of the strap and decreasing towards zero at the free edge. When the substrate crack propagates under the strap, cases (2) \& (3), higher stresses are picked up by the strap with a maximum stress at the delamination tip. Hence, as the crack propagates, the strap picks up more stresses from the cracked substrate.

The stress distribution in the substrate was influenced mainly by the presence of the crack tip. In the unstrapped area, the longitudinal stress was $70 \mathrm{MPa}$, for the free surface and bonded surface, corresponding to the nominal applied stress (not shown). Along the crack line, the stress increases to high levels as the crack tip is approached, Fig. 8 (c). This result arises from the linear elastic model used. In reality crack tip plasticity will occur where local stresses exceed the yield stress. In models for crack growth prediction, the stress intensity factor has been used to represent crack tip stress fields which then of course, are not explicitly calculated. Significant difference in stress between the free surface and the bonded surface was found, indicating the influence of the strap and the secondary bending. It also shows the crack is predicted to grow faster at the free surface than at the bonded surface. 

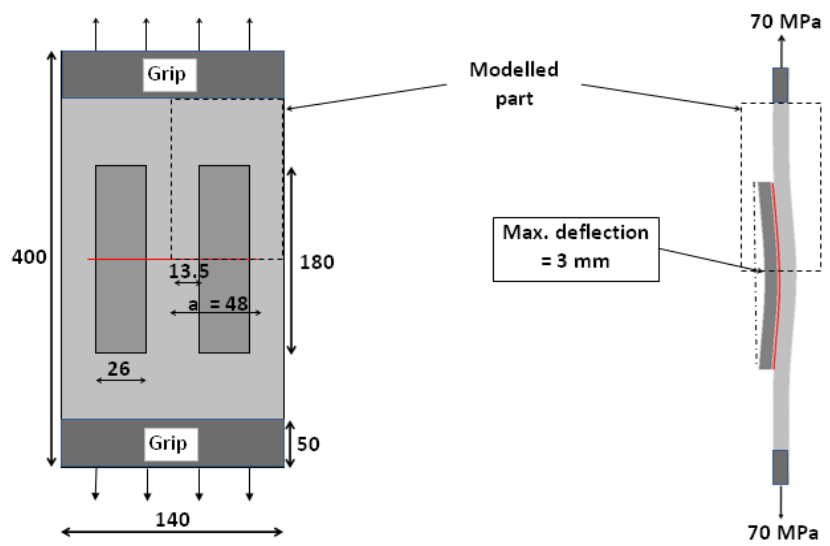

(a) $\mathrm{M}(\mathrm{T})$ sample geometry and modelling

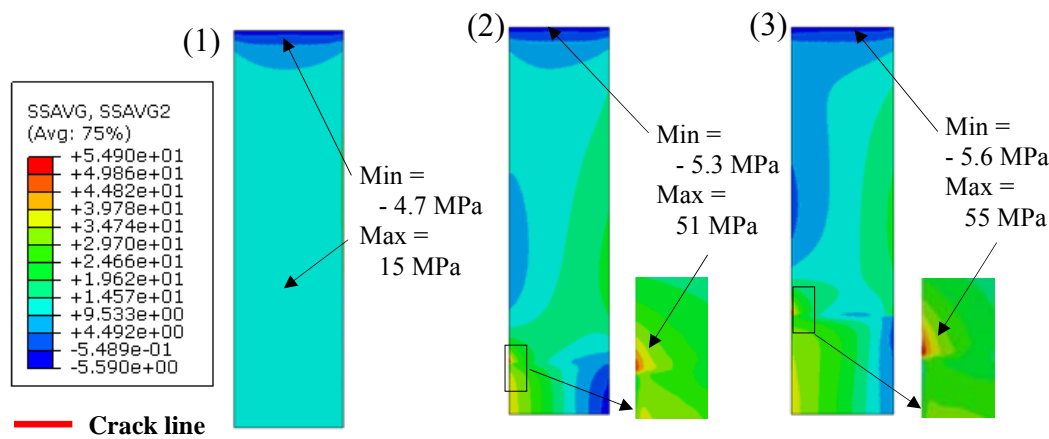

(b) Mean stress in strap: (1) no crack, (2) $26 \mathrm{~mm}$ half crack, and (3) $48 \mathrm{~mm}$ half crack ; half strap is shown (top line is the strap free edge)

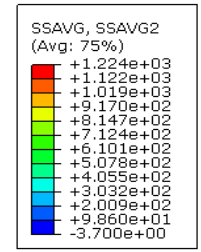

Crack line

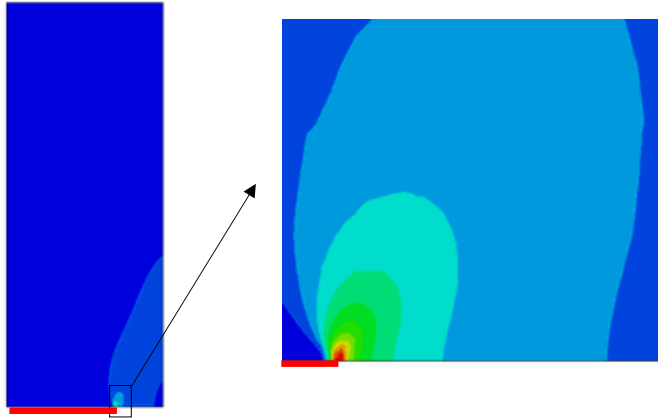

(c) Quarter of substrate: Mean stresses for the $48 \mathrm{~mm}$ crack

Fig. 8 Stresses in the $\mathrm{M}(\mathrm{T})$ samples for different crack lengths. 


\section{SKIN-STRINGER PANELS}

\section{Specimen and test setup}

To further test the principles of bonded crack retardation at a larger scale, a skinstringer panel representing the upper wing skin of a transport aircraft was designed and tested. The panel was made of AA 7085 and bonded retarder straps were made of GLARE and of 7085 alloy. A test panel is shown in Fig 9. It was $1200 \mathrm{~mm}$ long and $650 \mathrm{~mm}$ wide containing five integrally machined stringers. The stringer pitch was $130 \mathrm{~mm}$, with stringer thickness of $7 \mathrm{~mm}$ and a height of $50 \mathrm{~mm}$. The skin thickness at the thinnest areas was $4 \mathrm{~mm}$ and the skin-doubler thickness $6 \mathrm{~mm}$. The stringer cross-sectional area to skin bay area ratio $\left(A_{s t} / b t\right)$ is 0.838 . The initial damage scenario was an initial skin crack length of $22 \mathrm{~mm}$ under a broken central stringer.

Two strap materials were selected to reinforce the panel. The choice of strap materials and dimensions came from the data produced by the coupon tests and residual stress measurements reported earlier. Optimum strap materials should have coefficients of thermal expansion close or equal to that of the substrate. For this reason GLARE and AA7085 were chosen as strap materials. The most important variable in the design of a strap is the stiffness ratio. For the case of the AA7085 straps, the stiffness will be slightly greater than that of GLARE, and although the widths and lengths of the straps were identical to those used for the wide GLARE straps, the thickness was reduced to $3.25 \mathrm{~mm}$ to maintain the stiffness ratio at 0.2 . The straps were placed in the bays between the stringers with half bay widths at the panel edges.

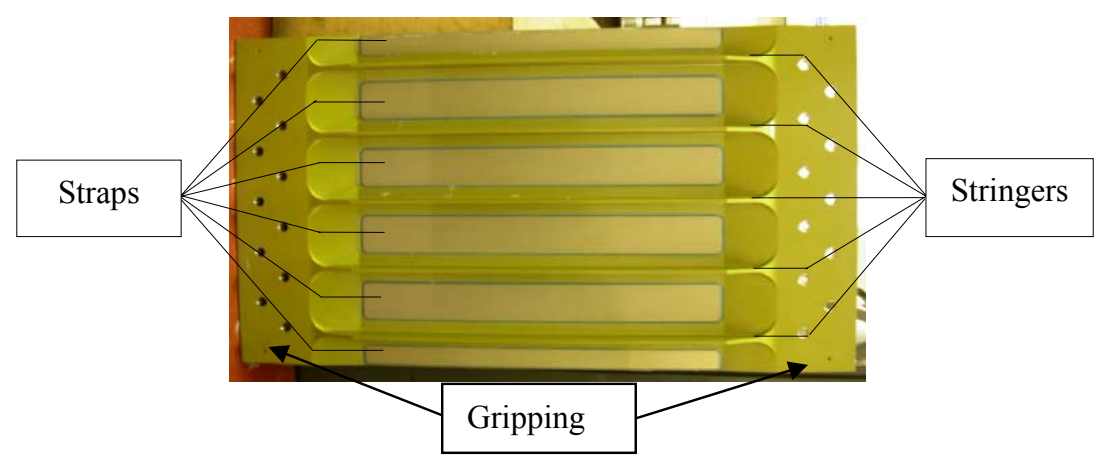

Fig. 9 Picture of panel with wide GLARE straps ready for testing.

The load spectrum was based on service strain measurements on the upper wing skin of a transport aircraft. It consisted originally of 21 different blocks each containing a sequence of up to 300 turning points. These were concatenated in a defined order with a total length of 4,800 blocks. The general form of the stress 
sequence is shown in Fig. 10 showing that the spectrum consists of load changes between a tensile mean of approximately $30 \mathrm{MPa}$, and a compressive mean of around 40-50 MPa. The spectrum was gated to remove smaller amplitude cycles, thus permitting completion of fatigue tests in a feasible length of time.

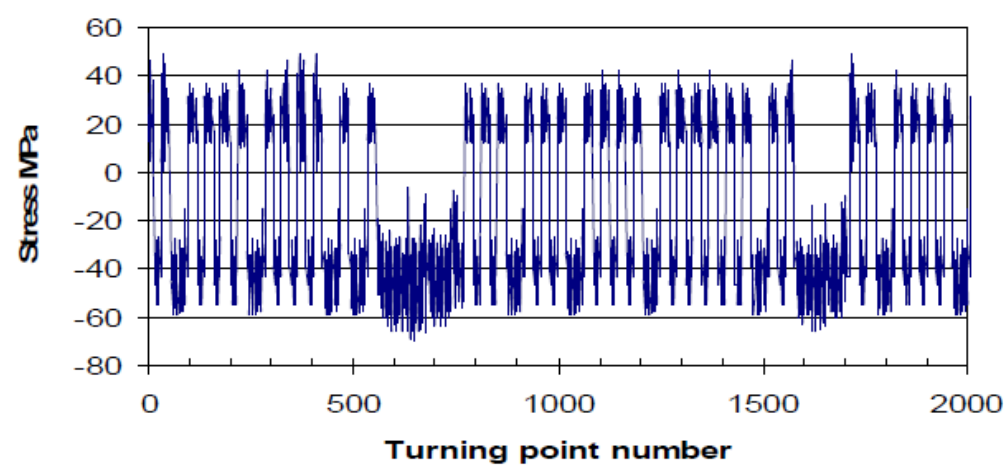

Fig. 10 First part of upper wing cover spectrum

Residual stress measurement in the test panels reinforced with GLARE

The residual stress field induced by thermal expansion mismatch between the strap and substrate was measured using neutron diffraction at the ENGIN-X instrument at the UK ISIS facility. Fig. 11 shows the longitudinal residual stresses in the panel skin reinforced with GLARE straps. The measurement was performed in the centre of the skin along the width of the specimen. The measured maximum residual stress was about $10 \mathrm{MPa}$. This shows a key advantage of the GLARE straps in that the coefficient of thermal expansion is close to that of the aluminium substrate so inducing low residual stress.

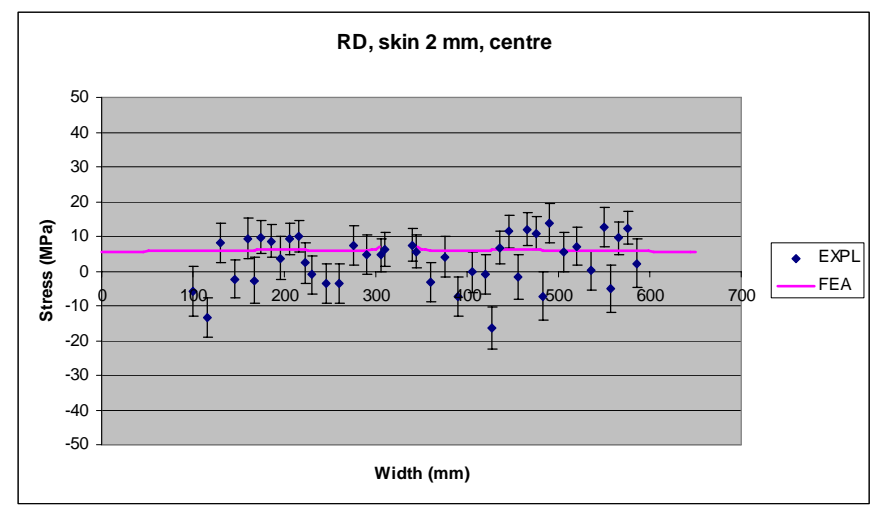

Fig. 11 Residual stresses in the panel substrate reinforced with wide GLARE strap. 


\section{Panel Fatigue Test results}

Figure 12 shows the plot of half crack length vs. cycles for the panel tests showing that initial behaviour of the three tests was similar up to a half crack length of 20$30 \mathrm{~mm}$. After this the unstrapped and strapped curves diverged with the unstrapped propagating at a much faster rate eventually failing at a skin crack length of 320 $\mathrm{mm}$, as the skin crack approached the second set of stringers. The tests of the wide GLARE and aluminium strapped panels were terminated where the skin crack was between 150-200 mm, largely for reasons of test time.

Examination of the failed unstrapped panel after test showed that the crack had become very asymmetric on the skin and on the stringer where the separate growth of the two sides is recorded. At the first stringer, the crack deviated parallel to the loading direction and no further propagation across the stringer occurred. Crack turning behaviour in 7085 has been observed on a number of occasions before in the course of the coupon test reported in the earlier sections of this report, and its occurrence in the stringer webs under conditions of stringer in plane bending is consistent with the observations made on the coupon samples.

In all the strapped tests, the crack on the stringer side approached and then tunnelled under the first strap. In the case of the panel with the wide GLARE straps the straps remained intact and the crack tip subsequently emerged on the other side of the strap, before entering the first pair of stringers. In the case of the wide aluminium strap, the substrate fatigue crack caused initiation of a fatigue crack in the strap itself, which then propagated together with the panel crack for the rest of the test duration.

In summary, the panel testing has shown that the wide GLARE straps work well, increasing the crack growth life of the panel compared with the unstrapped one by in excess of a factor of 2. Unlike the other strapped panels the wide GLARE ones remained intact throughout the test. The aluminium strap although it initially reduced crack growth rates to a smaller value than the GLARE straps as it had no thermal residual stresses, initiated a fatigue crack very soon after the crack tip tunnelled under it, and rapidly lost retardation capability.

Prediction

For the un-strapped panel, the predicted crack growth life is $22 \%$ shorter than the test result probably because: a) the load interaction model in the AFGROW may be inadequate to fully model a tension-compression loading history, and a compression dominated spectrum; b) After the first stringer the crack in the stringer turned to propagate parallel to the loading direction. This change of failure mode will slow down the crack growth rate of the skin crack and was not modelled. For the wide Glare strap reinforced panel, the predicted FCG life agrees very well with the test result, Fig. 13. For the wide aluminium strap reinforced panel, predicted FCG life is much longer than the test result as the fatigue failure of the strap (crack initiation and propagation) was not modelled. 


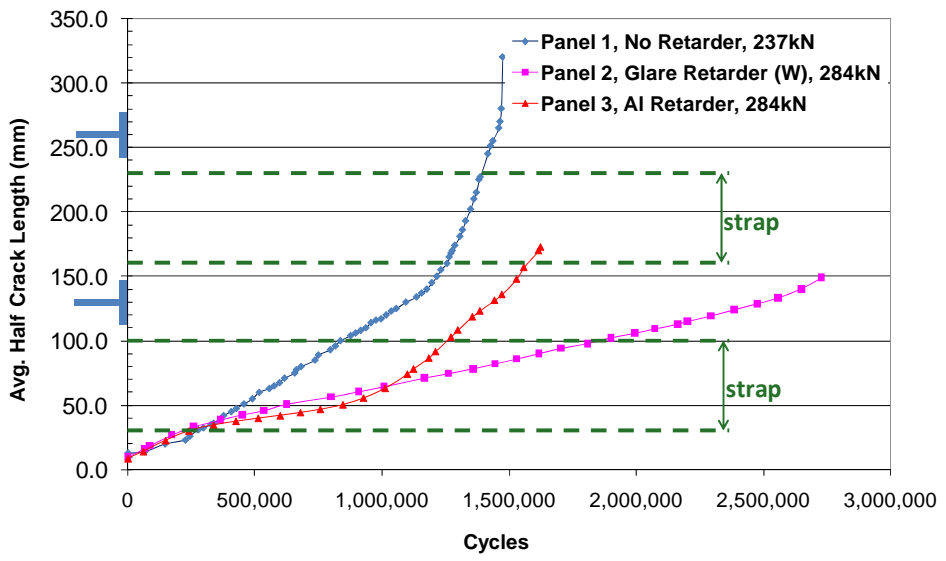

Fig. 12 Half crack length vs. cycles for panels tested under a flight spectrum.

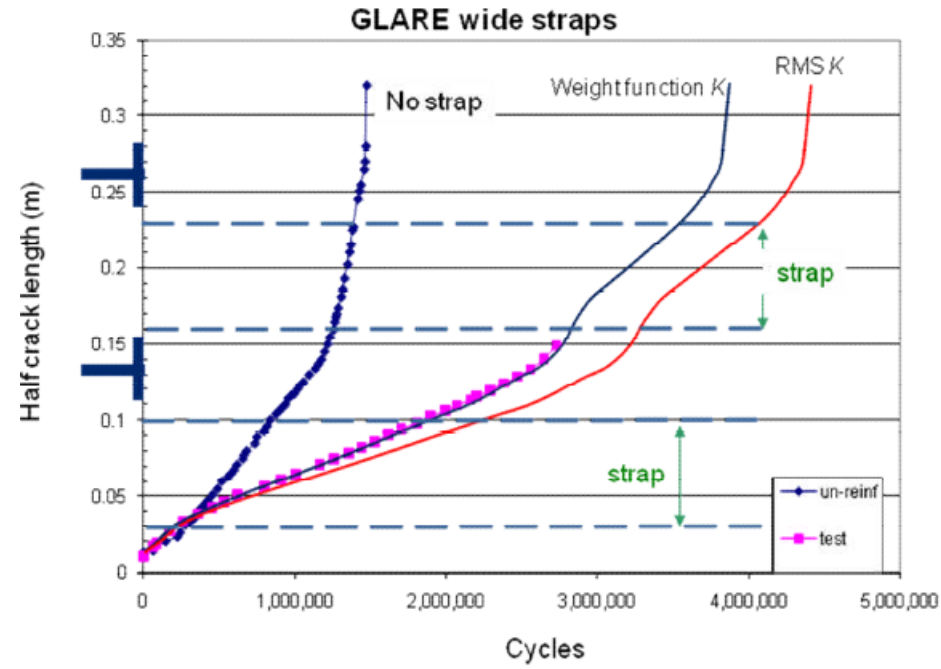

Fig. 13 Predicted and test measured crack growth lives (wide GLARE strap).

\section{FINAL DISCUSSION}

Bonded straps influence crack growth life in four major ways, which are: (1) by transferring stress locally away from the substrate; this reduces crack growth rates as the crack approaches the strap edge; (2) strap effectively bridging the crack as 
the crack tunnels under it, reducing the crack growth rates further; (3) delamination developed between the strap and the substrate stops the strap being fractured by the crack tip stress field but also increases substrate crack growth rates; (4) tensile residual stress fields created in the curing process accelerate the crack growth rates. The overall crack growth rates result from the combined influence of all the above.

In the absence of residual stresses, the stiffness ratio that is related to strap crosssection area and elastic modulus determines the extent of retardation caused by the strap. Residual stresses induced by the curing process at elevated temperature act in opposition; they accelerate crack growth rates. Of the strap materials studied, AA7085 and GLARE had the least residual stress and had best crack growth retardation performance. The finite element model is able to predict crack growth rates in many of the configurations studied.

Although AA7085 straps were best at substrate stresses up to $20 \mathrm{MPa}$, at $60 \mathrm{MPa}$, the stresses in the crack tip region were sufficient to initiate a crack in the strap, which then progressed together with the substrate crack with little subsequent retardation effect.

Due to the low elastic modulus in the GFRP strap material, stiffness ratio was kept low at 0.07 for most of the coupons. Therefore the life improvement factor found in this study is not generic for future designs. At higher stiffness ratio of 0.2 , the skin-stringer panels with wide GLARE or AA7085 straps have substantial life extension by a factor of 2 at stress levels increased by $20 \%$.

\section{CONCLUSIONS}

(1) The major parameter influencing retardation behaviour in the absence of residual stress is the global stiffness ratio, which represents the relative stiffness of both strap and substrate, incorporating modulus and cross section area.

(2) Residual stresses arising from elevated temperature curing are detrimental to retardation capability; with elevated temperature cure, strap materials having the closest match to substrate CTE such as GLARE are the best.

(3) Aluminium straps are superior to GLARE at low substrate stresses; stresses of $60 \mathrm{MPa}$ and above cause fatigue cracking of the aluminium strap.

(4) Under variable amplitude loading GLARE maintains its superiority as a strap material.

(5) The following effects have been modelled by finite element method:

a) Secondary bending due to one-side bonded strap;

b) Thermal residual stresses and redistribution due to crack growth;

c) Coupling of thermal and mechanical stresses;

d) Influence of disbond growth on lead crack tip stress intensity factors;

e) Strap size effect (variable width $\&$ thickness for a fix stiffness ratio). 


\section{ACKNOWLEDGEMENTS}

Cranfield University Innovative Manufacturing Research Centre (EPSRC) is thanked for sponsoring part of this work. The authors also wish to thank the UK ISIS neutron facility for access to the ENGIN-X instrument. MEF is supported by a grant through The Open University from The Lloyd's Register Educational Trust, an independent charity working to achieve advances in transportation, science, engineering and technology education, training and research worldwide for the benefit of all.

\section{REFERENCES}

[1] Holwerda, F (2002) in Around Glare a new material in context, Vermeeren, C. (Ed.) Kluwer, pp. 115-120

[2] Heinimann, M, Bucci, R, Kulak, M, Garratt, M. (2005). In: Structural integrity of advanced aircraft and life extension for current fleets, Proceedings of the 23rd ICAF Symposium, vol. I, pp. 197-208, Dalle Donne, C. (Ed.), Hamburg.

[3] Zhang, X, Figueroa-Gordon, D, Boscolo, M, Allegri, G, Irving, PE. (2007) In: Durability and damage tolerance of aircraft structures: metals vs. composites, Proceedings of the $24^{\text {th }}$ ICAF Symposium, Lazzeri, L., Salvetti, A. (Ed.), vol. I, pp. 188-205, Naples.

[4] Zhang, X, Boscolo, M, Figueroa-Gordon, D, Allegri, G, Irving, PE. (2009). Eng. Fract Mech, vol. 76, pp. 114-133.

[5] Plokker, M., Daverschot, D., Beumler, T. (2009). In: Bridging the gap between theory and operational practice, Proceedings of the 25th ICAF Symposium, Bos, M. (Ed.), Springer, pp. 375-385.

[6] Chakrabarti, DI, Lui, J, Sawtell, RR, Venema, GB (2004), New generation high strength high damage tolerance 7085 thick alloy product with low quench sensitivity, Materials Forum 28, Eds. Nie JF, Martin AJ, Muddle BC, pp 969-973; Inst Mat Eng Australasia Ltd.

[7] Liljedahl CDM, Fitzpatrick ME, (2010) Residual stresses in bonded crack retarders, Final report (unpublished), Open University.

[8] Liljedahl, CDM, Fitzpatrick, ME, Edwards, L. (2008) Composite Structures, 86: 344 .

[9] Bonded reinforcement and crack retarders in integral aluminium aircraft structures, Final Report (unpublished), Cranfield University, 2010.

[10] Boscolo, M, Zhang, X. (2010), Eng. Fract Mech, vol. 77, pp. 883-895.

[11] Boscolo, M, Zhang, X. (2010), Eng. Fract Mech, vol. 77, pp. 896-907. 